\title{
Flight Crew Survey Responses from the Interval Management (IM) Avionics Phase 2 Flight Test
}

\author{
Brian T. Baxley ${ }^{1}$, Kurt A. Swieringa ${ }^{2}$, Sara R. Wilson ${ }^{3}$, and Roy D. Roper ${ }^{4}$ \\ NASA Langley Research Center (LaRC), Hampton VA, 23681 \\ Clay E. Hubbs ${ }^{5}$, Paul A. Goess ${ }^{5}$, and Richard F. Shay ${ }^{6}$ \\ National Institute of Aerospace, Hampton, VA 23666
}

\begin{abstract}
The Interval Management (IM) Avionics Phase 2 flight test used three aircraft over a nineteen day period to operationally evaluate a prototype IM avionics. Quantitative data were collected on aircraft state data and IM spacing algorithm performance, and qualitative data were collected through end-of-scenario and end-of-day flight crew surveys. The majority of the IM operations met the performance goals established for spacing accuracy at the Achieveby Point and the Planned Termination Point, however there were operations that did not meet goals for a variety of reasons. While the positive spacing accuracy results demonstrate the prototype IM avionics can contribute to the overall air traffic goal, critical issues were also identified that need to be addressed to enhance IM performance. The first category was those issues that impacted the conduct and results of the flight test, but are not part of the IM concept or procedures. These included the design of arrival and approach procedures was not ideal to support speed as the primary control mechanism, the ground-side of the Air Traffic Management Technology Demonstration (ATD-1) integrated concept of operations was not part of the flight test, and the high workload to manually enter the information required to conduct an IM operation. The second category was issues associated with the IM spacing algorithm or flight crew procedures. These issues include the high frequency of IM speed changes and reversals (accelerations), a mismatch between the deceleration rate used by the spacing algorithm and the actual aircraft performance, and some spacing error calculations were sensitive to normal operational variations in aircraft airspeed or altitude which triggered additional IM speed changes. Once the issues in these two categories are addressed, the future IM avionics should have considerable promise supporting the goals of improving system throughput and aircraft efficiency.
\end{abstract}

\section{Nomenclature}

$A B P=$ Achieve-By Point

$A D S-B=$ Automatic Dependent Surveillance - Broadcast

ARTCC $=$ Air Route Traffic Control Center

ATD-1 = Air Traffic Management Technology Demonstration -1

$C G D=$ Configurable Graphics Display

EFB $\quad=\quad$ Electronic Flight Bag

$F L=$ Flight Level

FSI $=$ FAST/SLOW Indicator

GNSS = Global Navigation Satellite System

$I M$

KBFI $=$ Boeing Field / King County International Airport

${ }^{1}$ Research Engineer, Crew Systems and Aviation Operations Branch, NASA LaRC, AIAA Senior Member.

${ }^{2}$ Research Engineer, Crew Systems and Aviation Operations Branch, NASA LaRC, AIAA Member.

${ }^{3}$ Research Engineer, Systems Engineering and Engineering Methods Branch, NASA LaRC.

${ }^{4}$ Research Engineer, Crew Systems and Aviation Operations Branch, NASA LaRC.

${ }^{5}$ Aviation Consultant, All Aspect Aerospace Innovations LLC, Parker CO.

${ }^{6}$ Aviation Consultant, Double Black Aviation Technology LLC, Longmont CO, AIAA Senior Member. 


\begin{tabular}{|c|c|c|}
\hline KMWH & $=$ & Grant County International Airport \\
\hline KSEA & $=$ & Seattle-Tacoma International Airport \\
\hline LNAV/VNAV & $=$ & Lateral Navigation / Vertical Navigation \\
\hline MOPS & $=$ & Minimum Operational Performance Standards \\
\hline nmi & $=$ & nautical mile \\
\hline Ownship & $=$ & Aircraft with IM equipage \\
\hline$P B N$ & $=$ & Performance-Based Navigation \\
\hline$P F$ & $=$ & Pilot Flying \\
\hline$P M$ & $=$ & Pilot Monitoring \\
\hline PTP & $=$ & Planned Termination Point \\
\hline$R N A V$ & $=$ & Area Navigation \\
\hline$R N P A R$ & $=$ & Required Navigation Performance Authorization Required \\
\hline Target & $=$ & Aircraft the IM aircraft is assigned to follow \\
\hline TRACON & $=$ & Terminal Radar Approach Control \\
\hline
\end{tabular}

\section{Introduction}

JASA's first Air Traffic Management Technology Demonstration (ATD-1) is a research and development activity in the Airspace Operations and Safety Program with the primary goal to operationally demonstrate an integrated arrival management concept using three elements for planning and executing efficient arrival operations into the terminal environment of a high-density airport. ${ }^{1,2}$ These three elements, with their associated concepts and technologies developed to a significant degree by NASA, were the Traffic Management Advisor with Terminal Metering scheduler, the Controller-Managed Spacing decision support tools, and the Interval Management (IM) avionics. The operational goal of the integrated elements was to enable aircraft, using their onboard auto-flight systems, to plan for and fly performance-based navigation (PBN) procedures to the maximum extent possible, from cruise to the runway at a high-density airport, during peak traffic demand, primarily using speed control to meet the arrival schedule.

The IM element's contribution to the ATD-1 concept of operation is the spacing interval software that calculates the airspeed for the aircrew to fly to precisely achieve or maintain a spacing interval behind the Target (lead) aircraft. The IM avionics uses: 1) flight crew entered data (Ownship and Target aircraft routes and the controller provided IM clearance), 2) Ownship state data from the aircraft avionics bus, and 3) Target state data (location, heading, altitude, and speed) from Ownship's receipt of the Target's Automatic Dependent Surveillance - Broadcast (ADS-B) messages. This information is used by the IM avionics to calculate a specific airspeed to fly to either achieve, capture, or maintain the spacing interval assigned by the controller. The IM operation is conducted by the flight crew flying the airspeed displayed by the IM avionics described in section II.E from initiation until the Planned Termination Point (PTP).

The ATD-1 sub-project's research was instrumental in integrating the three elements and profoundly impacted the design of the NASA's version of the ATD-1 concept of arrival operations and the supporting IM procedures for flight crew. Sixteen human-in-the-loop experiments were conducted at NASA Ames and NASA Langley Research Centers, with some focusing on the ground tools, some the IM tools and procedures, and some the integrated concept (see Appendix C of ref. 2 for a list of the experiments, as well as their objectives, findings, and publications). For the first two elements, the advanced arrival management scheduler and controller decision support tools enabling increased use of PBN procedures, the work culminated with an evaluation at the FAA's William J. Hughes Technical Center in May 2015, and NASA providing information and analysis to the FAA to be incorporated in a NextGen capability called Terminal Sequencing and Spacing. ${ }^{3}$

For the third element, the IM avionics and procedures, simulation research occurred in parallel with work contracted to industry partners from 2014 through 2017. The final simulation experiment was the Interval Management Alternative Clearances human-in-the-loop simulation at NASA Langley Research Center in $2015^{4-6}$, and its results provided significant input into the design and format of the Avionics contracts. The Avionics Phase 1 contract with Boeing was to conduct feasibility analysis and trade studies, develop an IM avionics engineering prototype, and provide recommendations for the Avionics Phase 2 contract. $^{7}$ In Decmeber 2014 a flight test was conducted in association with the ATD-1 Avionics Phase 1, and it used a laptop computer with NASA's IM spacing algorithm installed on it to provide airspeed cues to the flight crew. This Avionics Phase 1 flight test provided useful data about the spacing algorithm, and established working relationships with the air traffic control facilities that were critical to the success of the Phase 2 flight test. ${ }^{8-9}$ 
The ATD-1 Avionics Phase 2 included systems engineering, hardware development, IM application development, system validation testing, aircraft integration, and planning and execution of a multi-aircraft flight test. In early 2017, the Avionics Phase 2 flight test was conducted over nineteen days in the vicinity of the Grant County International Airport (KMWH), Washington. Boeing Research and Technology (prime contractor) with Boeing Commercial Aircraft, Honeywell, United Airlines, and Jeppesen (sub-contractors) developed a comprehensive plan for the flight test. ${ }^{10-11}$ Since the ATD-1 advanced scheduler and controller decision support tools were not available for this flight test, the NASA research team developed specific airspeed profiles for the first aircraft to fly to emulate the behavior expected in an integrated operational environment. In addition to system delay, the aviation community, and in particular the FAA Surveillance and Broadcast Services (SBS) team, defined other parameters of interest that drove the development of the flight test matrix. ${ }^{12-13}$

This paper provides a cursory overview of performance and nominal operation, and then focuses on the flight crew responses recorded in the ATD-1 Avionics Phase 2 flight test end-of-scenario and end-of-day surveys. A separate paper is available that provides additional results focusing on quantitative measures. ${ }^{14}$

\section{Experiment Design}

\section{A. Test Matrix}

The ATD-1 Avionics Phase 2 flight test was designed to evaluate IM avionics performance in three phases of flight: en route ("A" scenarios), arrival ("B" scenarios), and final approach ("C" scenarios). The scenarios were structured in the test matrix (Table 1) to allow an examination of the following independent variables:

- IM clearance type (Cross, Capture, Maintain, or Final Approach Spacing) (see ref. 14 for more detail)

- Spacing error (aircraft's position relative to location desired by the simulated schedule)

- Spacing type (time in seconds or distance in tenths of nautical miles)

- Lead aircraft required delay to absorb (none, medium, or high)

- Achieve-by Point (ABP) location ("Cross-Merge" where the routes merged at a medium-altitude point (NALTE), or "Cross-FAF" where the routes merged at the final approach fix (ZAVYO))

- Aircraft route geometry

Table 1. Text Matrix for ATD-1 Avionics Phase 2 flight test

\begin{tabular}{|c|c|c|c|c|c|c|c|c|c|c|c|c|c|c|c|c|c|c|}
\hline Scenario & Tgt Route & \begin{tabular}{|c|} 
Tgt Delay \\
(see TgtRts)
\end{tabular} & $\begin{array}{c}\text { FIM1 CInc } \\
\text { Type }\end{array}$ & FIM1 T/D & FIM1 Route & $\begin{array}{l}\text { FIM1 } \\
\text { SpErr }\end{array}$ & $\begin{array}{l}\text { FIM1 } \\
\text { ABP }\end{array}$ & $\begin{array}{l}\text { FIM1 } \\
\text { PTP } \\
\end{array}$ & $\begin{array}{c}\text { FIM2 CInc } \\
\text { Type }\end{array}$ & FIM2 T/D & FIM2 Route & $\begin{array}{l}\text { FIM2 } \\
\text { SpErr }\end{array}$ & $\begin{array}{l}\text { FIM2 } \\
\text { ABP }\end{array}$ & $\begin{array}{l}\text { FIM2 } \\
\text { PTP } \\
\end{array}$ & $\begin{array}{c}\begin{array}{c}\text { Priority } \\
\text { Level }\end{array} \\
\end{array}$ & \begin{tabular}{|l|}
$\begin{array}{l}\text { \# of } \\
\text { Runs }\end{array}$ \\
\end{tabular} & $\begin{array}{c}\text { Rep } \\
1 \\
\end{array}$ & $\begin{array}{c}\text { Rep } \\
2 \\
\end{array}$ \\
\hline $\mathrm{A1}$ & en route & $0(.78 \mathrm{M})$ & CROSS & Time & en route & $+20 \mathrm{sec}$ & JELVO & MAHTA & CROSS & Time & en route & $-15 \mathrm{sec}$ & JELVO & MAHTA & $\mathrm{L}$ & 2 & 9 & 11 \\
\hline $\mathrm{A}_{2}$ & en route & $0(.78 \mathrm{M})$ & CROSS & Distance & en route & $+3 \mathrm{NM}$ & JELVO & MAHTA & CROSS & Distance & en route & $-2 \mathrm{NM}$ & JELVO & MAHTA & L & 2 & 10 & 12 \\
\hline A3 & en route & $0(.78 \mathrm{M})$ & CAPTURE & Time & en route & $+20 \mathrm{sec}$ & na & JELVO & CAPTURE & Time & en route & $-15 \mathrm{sec}$ & na & JELVO & H & 2 & 1 & 6 \\
\hline A4 & en route & $0(.78 \mathrm{M})$ & CAPTURE & Distance & en route & $+3 \mathrm{NM}$ & na & JELVO & CAPTURE & Distance & en route & $-2 \mathrm{NM}$ & na & JELVO & H & 2 & 2 & 5 \\
\hline A5 & en route & $0(.78 \mathrm{M})$ & MAINTAIN & Time & en route & na & na & JELVO & MAINTAIN & Time & en route & na & na & JELVO & M & 2 & 4 & 7 \\
\hline A6 & en route & $0(.78 \mathrm{M})$ & MAINTAIN & Distance & en route & na & na & JELVO & MAINTAIN & Distance & en route & na & na & JELVO & M & 2 & 3 & 8 \\
\hline B1 & JELVO.SUBDY & No Delay & CROSS & Time & ZIRAN.SUBDY & -20 & NALTE & FAF & CAPTURE & Time & ZIRAN.SUBDY & +30 & na & FAF & $\mathrm{H}$ & 2 & 4 & 34 \\
\hline B2 & ZIRAN.SUBDY & No Delay & CROSS & Time & JELVO.SUBDY & 0 & PTP & FAF & MAINTAIN & Time & JELVO.SUBDY & na & na & FAF & H & 2 & 14 & 35 \\
\hline B3 & ZIRAN.SUBDY & No Delay & CROSS & Time & JELVO.SUBDY & +60 & PTP & FAF & CROSS & Time & TRAKX.UPBOB & +30 & PTP & FAF & H & 2 & 12 & 27 \\
\hline B4 & JELVO.SUBDY & No Delay & CAPTURE & Time & JELVO.SUBDY & -60 & na & FAF & MAINTAIN & Time & JELVO.SUBDY & na & na & FAF & H & 2 & 5 & 29 \\
\hline B5 & JELVO.SUBDY & No Delay & CAPTURE & Time & JELVO.SUBDY & +60 & na & FAF & CROSS & Time & TRAKX.UPBOB & +30 & PTP & FAF & H & 2 & 11 & 30 \\
\hline B6 & JELVO.SUBDY & No Delay & MAINTAIN & Time & JELVO.SUBDY & na & na & FAF & CROSS & Time & ZIRAN.SUBDY & +15 & NALTE & FAF & $\mathrm{H}$ & 2 & 9 & 39 \\
\hline B7 & JELVO.SUBDY & Med Delay & CROSS & Time & ZIRAN.SUBDY & -20 & NALTE & FAF & CAPTURE & Time & ZIRAN.SUBDY & +30 & na & FAF & M & 2 & 16 & 43 \\
\hline B8 & ZIRAN.SUBDY & Med Delay & CROSS & Time & JELVO.SUBDY & 0 & PTP & FAF & MAINTAIN & Time & JELVO.SUBDY & na & na & FAF & M & 2 & 22 & 40 \\
\hline B9 & ZIRAN.SUBDY & Med Delay & CROSS & Time & JELVO.SUBDY & +60 & PTP & FAF & CROSS & Time & TRAKX.UPBOB & +30 & PTP & FAF & M & 2 & 20 & 47 \\
\hline B10 & JELVO.SUBDY & Med Delay & CAPTURE & Time & JELVO.SUBDY & -60 & na & FAF & MAINTAIN & Time & JELVO.SUBDY & na & na & FAF & M & 2 & 18 & 42 \\
\hline B11 & JELVO.SUBDY & Med Delay & CAPTURE & Time & JELVO.SUBDY & +60 & na & FAF & CROSS & Time & TRAKX.UPBOB & +30 & PTP & FAF & M & 2 & 23 & 45 \\
\hline B12 & JELVO.SUBDY & Med Delay & MAINTAIN & Time & JELVO.SUBDY & na & na & FAF & CROSS & Time & ZIRAN.SUBDY & +15 & NALTE & FAF & M & 2 & 24 & 44 \\
\hline B13 & JELVO.SUBDY & High Delay & CROSS & Time & ZIRAN.SUBDY & -20 & NALTE & FAF & CAPTURE & Time & ZIRAN.SUBDY & +30 & na & FAF & $\mathrm{H}$ & 2 & 1 & 33 \\
\hline B14 & ZIRAN.SUBDY & High Delay & CROSS & Time & JELVO.SUBDY & 0 & PTP & FAF & MAINTAIN & Time & JELVO.SUBDY & na & na & FAF & H & 2 & 3 & 26 \\
\hline B15 & ZIRAN.SUBDY & High Delay & CROSS & Time & JELVO.SUBDY & +60 & PTP & FAF & CROSS & Time & TRAKX.UPBOB & +30 & PTP & FAF & $H$ & 2 & 2 & 37 \\
\hline B16 & JELVO.SUBDY & High Delay & CAPTURE & Time & JELVO.SUBDY & -60 & na & FAF & MAINTAIN & Time & JELVO.SUBDY & na & na & FAF & $\mathrm{H}$ & 2 & 8 & 31 \\
\hline B17 & JELVO.SUBDY & High Delay & CAPTURE & Time & JELVO.SUBDY & +60 & na & FAF & CROSS & Time & TRAKX.UPBOB & +30 & PTP & FAF & H & 2 & 15 & 25 \\
\hline B18 & JELVO.SUBDY & High Delay & MAINTAIN & Time & JELVO.SUBDY & na & na & FAF & CROSS & Time & ZIRAN.SUBDY & +15 & NALTE & FAF & $\mathrm{H}$ & 2 & 13 & 32 \\
\hline B19 & ZIRAN.SUBDY & No Delay & CROSS & Time & JELVO.SUBDY & +20 & NALTE & FAF & CROSS & Time & ZIRAN.SUBDY & +15 & NALTE & FAF & $\mathrm{H}$ & 2 & 7 & 36 \\
\hline B20 & ZIRAN.SUBDY & Med Delay & CROSS & Time & JELVO.SUBDY & +20 & NALTE & FAF & CROSS & Time & ZIRAN.SUBDY & +15 & NALTE & FAF & H & 2 & 6 & 38 \\
\hline B21 & ZIRAN.SUBDY & High Delay & CROSS & Time & JELVO.SUBDY & +20 & NALTE & FAF & CROSS & Time & ZIRAN.SUBDY & +15 & NALTE & FAF & H & 2 & 10 & 28 \\
\hline B22 & ZIRAN.SUBDY & No Delay & CROSS & Distance & JELVO.SUBDY & $+2 \mathrm{~nm}$ & PTP & FAF & CROSS & Distance & ZIRAN.SUBDY & $+1 \mathrm{~nm}$ & PTP & FAF & M & 2 & 21 & 46 \\
\hline B23 & ZIRAN.SUBDY & Med Delay & CROSS & Distance & JELVO.SUBDY & $+2 \mathrm{~nm}$ & PTP & FAF & CROSS & Distance & ZIRAN.SUBDY & $+1 \mathrm{~nm}$ & PTP & FAF & M & 2 & 17 & 41 \\
\hline B24 & ZIRAN.SUBDY & High Delay & CROSS & Distance & JELVO.SUBDY & $+2 \mathrm{~nm}$ & PTP & FAF & CROSS & Distance & ZIRAN.SUBDY & $+1 \mathrm{~nm}$ & PTP & FAF & M & 2 & 19 & 48 \\
\hline C1 & Str-in & No Delay & FINAL & Time & Str-in & $+15 \mathrm{sec}$ & PTP & 6.25 & & & & & & & M & 2 & 4 & 10 \\
\hline C2 & Str-in & No Delay & FINAL & Distance & Str-in & $+1 \mathrm{NM}$ & PTP & 6.25 & & & & & & & H & 2 & 1 & 7 \\
\hline C3 & Str-in & No Delay & FINAL & Time & Turn & $+15 \mathrm{sec}$ & PTP & 6.25 & & & & & & & M & 2 & 5 & 12 \\
\hline C4 & Str-in & No Delay & FINAL & Distance & Turn & +1 NM & PTP & 6.25 & & & & & & & $\mathrm{H}$ & 2 & 2 & 8 \\
\hline C5 & Turn & No Delay & FINAL & Time & Str-in & $+15 \mathrm{sec}$ & PTP & 6.25 & & & & & & & M & 2 & 6 & 11 \\
\hline C6 & Turn & No Delay & FINAL & Distance & Str-in & $+1 \mathrm{NM}$ & PTP & 6.25 & & & & & & & $\mathrm{H}$ & 2 & 3 & 9 \\
\hline 67 & Str-in & High Delay & FINAL & Distance & Turn & +1 NM & PTP & 6.25 & & & & & & & L & 2 & 14 & 16 \\
\hline 68 & Turn & High Delay & FINAL & Distance & Str-in & $+1 \mathrm{NM}$ & PTP & 6.25 & & & & & & & $\mathrm{~L}$ & 2 & 13 & 15 \\
\hline
\end{tabular}


Two replicates of 62 unique test conditions were planned for a total of 124 scenarios, each representing an IM operation within the context of this flight test. The scenario order was designed to ensure that the highest priority scenarios were flown, while also minimizing the impact of systematic bias and order effects on the results. The replicates of each scenario were assigned a priority level and the order was randomized within each priority level. More scenarios were flown per day than originally planned, resulting in more than the 124 scenarios described in Table 1. However, some scenarios were not included in the data analysis due to problems with setup or software issues with the prototype IM avionics, and scenarios A1, A2, C7, and C8 were intentionally not flown to allow for more flights of higher priority scenarios. The outcome was 144 scenarios (IM operations within the construct of this flight test) were completed and used in the data set reported in this paper.

\section{B. Air Traffic Facilities and Procedures}

Five air traffic control facilities participated in the ATD-1 Phase 2 flight test. The tower facilities at Boeing Field (KBFI) and Seattle-Tacoma International Airport (KSEA) coordinated with the Seattle Terminal Radar Approach Control (TRACON) to facilitate the setup of the first flight test scenario of the day. The Seattle Air Route Traffic Control Center (ZSE ARTCC) provided control for the en route scenarios and the first half of each arrival scenario prior to transferring the aircraft to the Moses Lake TRACON. The Moses Lake TRACON controlled the second half of each arrival scenario, facilitated the set-up of the next arrival scenario prior to handing the aircraft back to Seattle ARTCC, and controlled all of the merge on final approach scenarios.

Six special Standard Terminal Arrival Routes (STARs) were developed by Boeing and Jeppensen to facilitate the transition from the high-altitude en route environment into KMWH by connecting to the existing published Required Navigation Performance Authorization Required (RNP AR) instrument approach procedures at the airport. The arrival routes were also designed to allow for various combinations of merge points and route geometries, and connected to the instrument approaches to allow landing on either runway as the wind or other traffic dictated. The desire was to fly all scenarios to the runway 32R approach, since it had both a published straight-in and a published RNP curved approach that merged at the final approach fix. Moses Lake TRACON was able to support this request, and shown in Figure 1 are the STARs connecting to the runway 32R approaches.

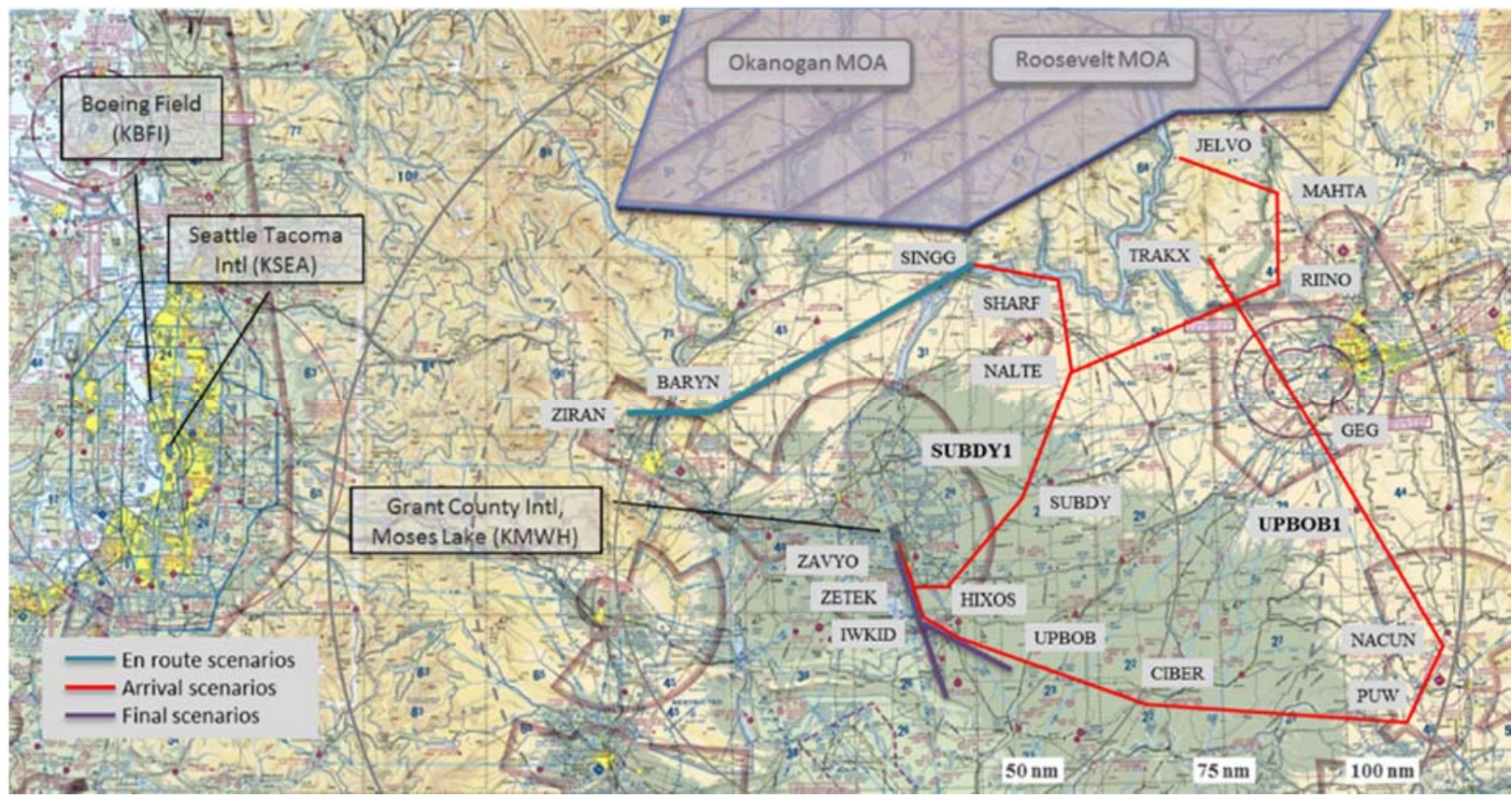

Figure 1. Flight test environment.

The en route scenarios were conducted at Flight Level (FL) 350 from ZIRAN to SINGG (blue-green line), with the first arrival scenario (red line) initiated immediately after the aircraft crossed SINGG. All subsequent arrival scenarios were initiated at FL230 to reduce transit time from the go-around point to the next start point, to avoid traffic inbound to or departing from the Seattle area above FL240, and to reduce controller workload by avoiding a handoff to a different air traffic control sector. The final approach spacing scenarios (purple lines) involved only two aircraft 
climbing to 6000 and 7000 feet, then proceeding to the start points approximately 30 nautical miles (nmi) south of KMWH.

\section{Aircraft and Flight Crew}

A Honeywell Dassault Falcon 900 (center aircraft in Figure 2) was used as the first aircraft in the flight test arrival stream. It was equipped with ADS-B Out and a Global Navigation Satellite System (GNSS), and is authorized to fly the published RNP AR approaches. A Honeywell Boeing-757 (B-757) (left aircraft in Figure 2) and a United Boeing737 (B-737) (right aircraft in Figure 2) were equipped with the prototype IM avionics. Both aircraft were also equipped with ADS-B, GNSS, and are authorized to fly the RNP AR approaches.

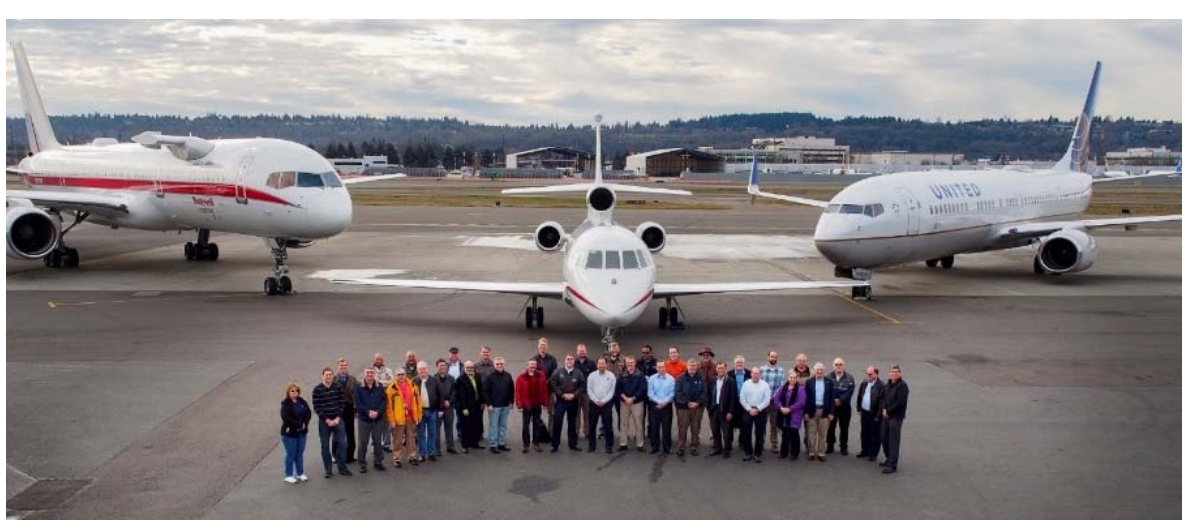

Figure 2. Aircraft used in ATD-1 Phase 2 flight test.

Flight crews were selected by their respective flight departments, and were current and qualified to fly the aircraft in the position(s) they occupied during the flight test. The flight crews flying the Falcon 900 were not treated as test subjects, and no qualitative data were collected from them. The four B-757 and four B-737 flight crews were test subjects, and both quantitative data (deviation from IM speed, response time to IM speed change, etc.) and qualitative data (surveys) were collected. The subjects ranged in age from late 20's to early 60's, and had a diverse background in terms of hours, qualifications, and experience with flight test. Prior to commencing the flight test, all subject pilots received computer-based training about the prototype IM avionics and flight crew procedures, and attended a four-day training session at NASA Langley Research Center.

\section{IM Avionics}

Figure 3 shows the prototype electronic flight bag (EFB) and configurable graphics display (CGD) devices used during the flight test to conduct IM operations. Each pilot in the two-person crew had their own EFB mounted on the outboard panel outside the primary field of view, and a CGD inside the primary field of view (B-757 above the glare shield, the B-737 on the front console). Since the EFBs were mounted outside the flight crew's optimal primary field of view, the CGD was specifically designed to automatically display the critical subset of information needed to conduct the operation to the flight crew, in particular the IM messages

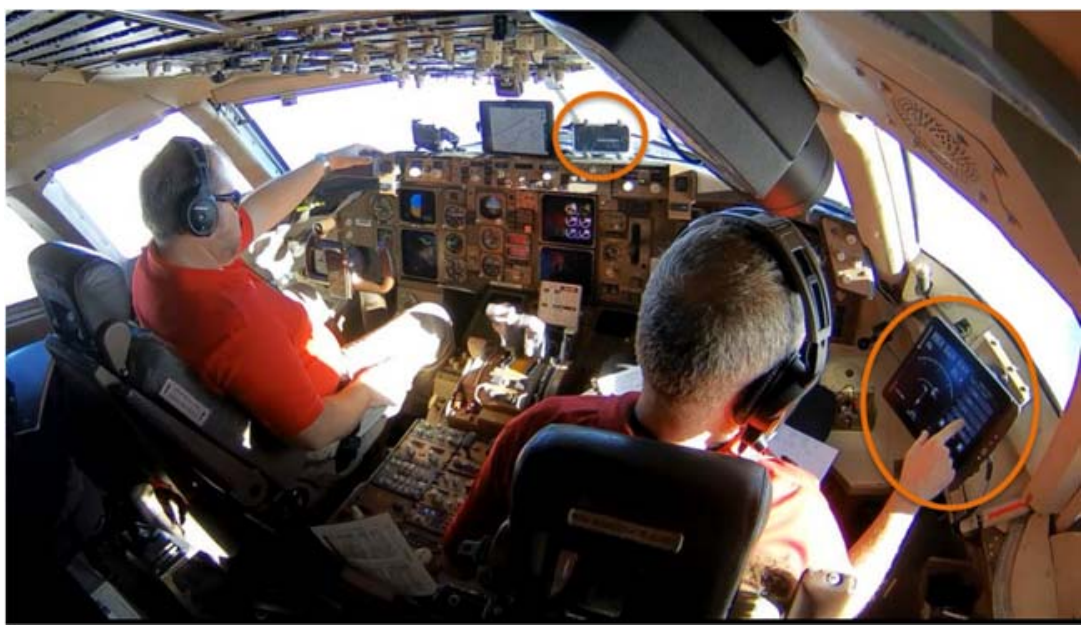

Figure 3. B-757 cockpit location of CGD (center circle) and EFB (right circle). and IM commanded speed.

The B-757 and B-737 had a Honeywell Traffic Processing Unit for ADS-B In track processing, which was utilized by the IM application hosted on the EFB. The EFB (right side of Figure 3) hosted the prototype IM application, had a touchscreen for data entry and application control, displayed the flight crew entered data and application data from the IM avionics, displayed surrounding air traffic for awareness, and provided data to the CGD (right side of Figure 3) via a wireless router located in the rear of the cockpit. The prototype IM avionics created by Honeywell was based 
on NASA ${ }^{15}$ and RTCA ${ }^{16}$ documents, while the EFB displays ${ }^{17}$ and the CGD displays ${ }^{18}$ were based on by an earlier NASA design. ${ }^{19}$ There was no data flow from the prototype IM avionics to certified avionics.

Figure 4 illustrates the prototype IM displays aligned with the example in section III.A where the Target is approaching NALTE and the Ownship has just passed OYOSE. Left to right, a subset of pertinent display elements include the:

- Target aircraft: shown with outer green chevron (and data tag if selected), otherwise shown in white

- Fast/Slow Indicator (FSI): depicts Ownship's deviation from the IM instantaneous speed (a continuous and smooth speed curve calculated to account for pilot reaction time and aircraft deceleration rate from the previous to the current IM commanded speed); centered means on the deceleration curve

- Progress Indicator: shown only when the aircraft is within 210 seconds of the ABP, and depicts Ownhip's position deviation from the controller assigned spacing goal as Early/Late (time-based) or as Near/Far (distance-based); centered means the Ownship is at the assigned spacing interval [Figure 4 correctly illustrates flight tested software in that when greater than 210 seconds from ABP, the labels were not shown on the EFB but were shown on the CGD.]

- IM commanded speed: speed the flight crew sets in Mode Control Panel to decelerate or accelerate to; displayed in reverse video (i.e., the color of the speed value and the color of the background are reversed) when a new IM commanded speed is issued; displayed as flashing reverse video (cycle from normal to reverse video) when the MOPS speed conformance monitoring status is not met (ref. 16, para 2.2.4.5.4).

- IM state: shows state of IM operation - in green if Paired, (i.e., all initiation criteria have been met and the flight crews are conducting the IM operation, or defined as the "Execute" state in paragraph 2.3.1 of reference 16), all other states shown in white

- IM clearance type: shows entered type in green when Paired, all other states shown in white

- Assigned Spacing Goal: time or distance value assigned by controller for the Ownship to achieve behind the Target aircraft by the ABP (Cross operations) or to achieve at a minimum rate of closure (Capture and Final Approach Spacing operations); calculated by the prototype IM avionics for Maintain operations; shown in seconds (time-based) or tenths of nmi (distance-based); shown in blue only when in Paired state [note: since all scheduling element of the ATD-1 concept of operations was not part of the this flight test, the ASG was given by the Flight Test Director in accordance with the test matrix in lieu of the controller issuing the ASG in accordance with the schedule]

- Predicted Spacing Interval: the IM avionics' estimate of the spacing interval at the Achieve-by Point in seconds or tenths of nmi (only applicable in the Cross clearance); for time-based spacing goals, the Predicted Spacing Interval is the difference in times that the IM and Target Aircraft are predicted to cross the Achieve-by Point; for distance-based spacing goals, the Predicted Spacing Interval is the predicted distance of the IM Aircraft when the Target Aircraft is predicted to cross the Achieve-by Point; calculated but not shown to flight crew in ref. 14 and 15; however, during the flight test, it was always shown in white when available to compensate for not having any ATD-1 ground tools (used by flight test director and flight crews to set up the scenario)

- Measured Spacing Interval: the IM system's calculation of the spacing interval when the IM Operation is in the Maintain Stage (the IM and Target aircraft must be in-trail); for time-based spacing goals, the Measured Spacing Interval is the time elapsed since the Target Aircraft crossed the IM Aircraft's current along-path position; for distance-based spacing goals, the Measured Spacing Interval is the along-path distance between the IM and Target Aircraft

The CGD repeated four essential display elements from the EFB (FSI, Progress Indicator, IM commanded speed, and IM state) and a subset of the IM avionics status messages. The colors were changed to white and the font size made larger to compensate for some of the devices being located above the glare shield and exposed to direct sunlight.

American Institute of Aeronautics and Astronautics 


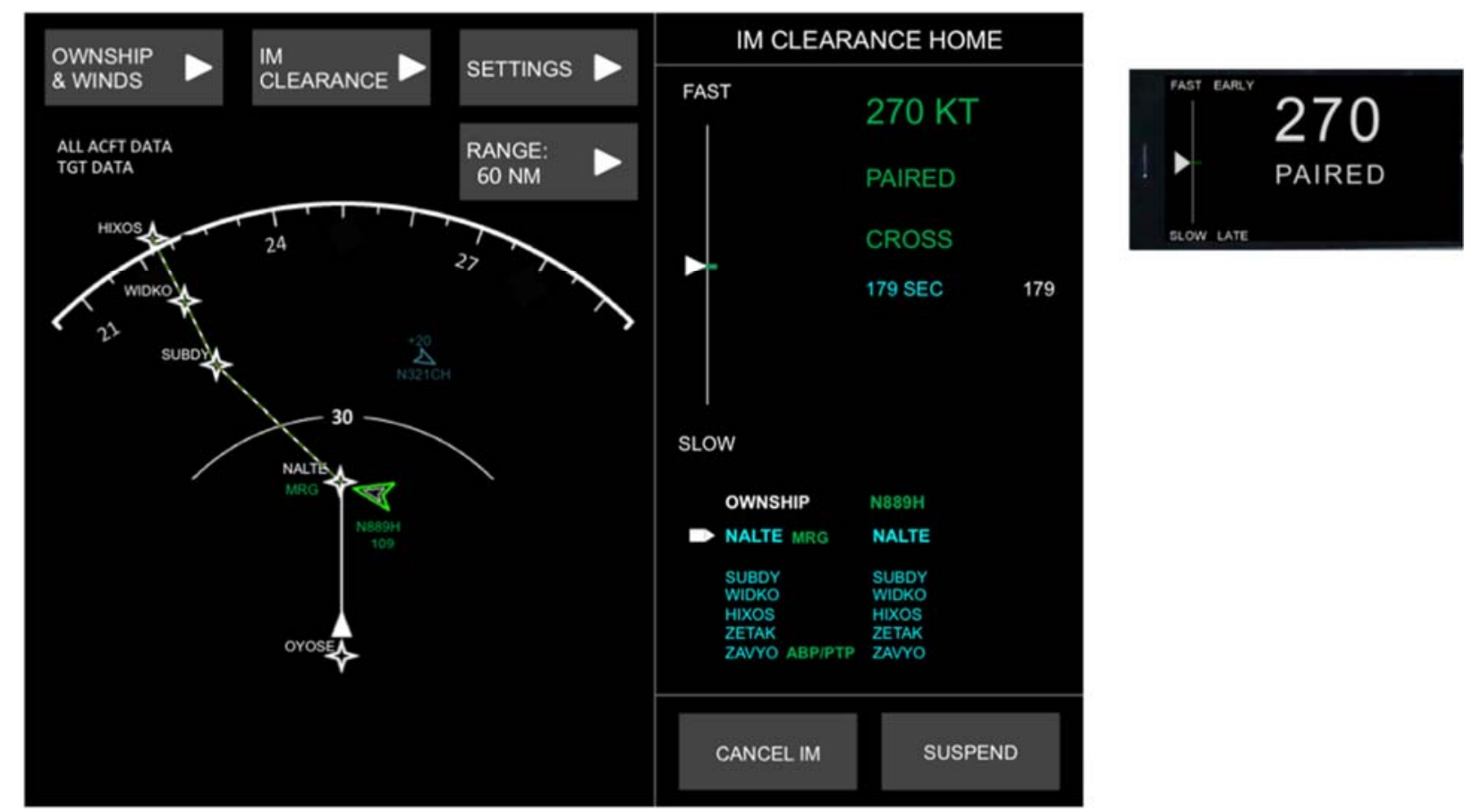

Figure 4. IM prototype EFB (left) and CGD (right).

\section{E. IM Operation Types and Flight Crew Procedures}

The four IM operation types in this flight test were each designed to achieve a particular operational goal: ${ }^{16}$

- Cross: Achieve an assigned spacing goal by the ABP, then maintain that spacing interval until the PTP. The prototype IM avionics uses a trajectory-based speed control law prior to the ABP, and a state-based speed control law (the same as Capture and Maintain) after the ABP. To achieve the operational goal, the $\mathrm{ABP}$ and PTP can be specified as the same waypoint or different waypoints.

- Capture: Capture the assigned spacing goal as quickly as possible (no slower than a minimum closure rate), then maintain that spacing interval to the PTP. Since both aircraft must be on the same route, the Capture operation does not require the prototype avionics to know the Target aircraft's trajectory and therefore the state-based speed control law is used throughout this operation type.

- Maintain: Maintain the initial spacing interval between the Ownship and Target aircraft until the PTP. Since both aircraft are on the same route, the prototype IM avionics uses the state-based speed control law throughout this operation type. This is the only IM operation type where a spacing goal is not provided.

- Final Approach Spacing: This is a special subset of the Cross operation type designed to be initiated in terminal airspace. When initiated, the IM avionics makes assumptions to determine both the Ownship and Target aircraft trajectories and uses the trajectory-based speed control law to a PTP as defined in RTCA DO-361 as $6.25 \mathrm{nmi}$ from the runway threshold ${ }^{16}$. The Final Approach operation type can begin when one aircraft is established on final approach and the other aircraft is either established on final approach or on a track less than 45 degrees from the final approach course.

The flight crews complied with published procedures and air traffic control instructions as they do during current real-world operations, with the additional task of flying the IM speed which supersedes the speed constraints on the published procedure. A design goal of the flight crew procedures for this flight test was to fit into the normal workflow of the flight crew, and every attempt was made to mirror normal arrival procedures. The procedures were divided into three distinct phases: 1) programming the IM avionics using the EFB, 2) using the prototype IM avionics while flying in vertical navigation (VNAV) speed mode en route or on arrival, and 3) using the prototype IM avionics while flying in VNAV path mode during the instrument approach. ${ }^{17}$

In the first phase of each scenario, the flight crew used the EFB to enter information about the Ownship route and destination, forecast en route and descent winds, and the IM clearance itself. In the second phase of each scenario, the flight crew used the prototype IM avionics while flying in VNAV speed, which given the capabilities of the two flight test aircraft, meant the aircraft pitched to achieve the new IM commanded speed (increase the descent rate to accelerate 
or decease the descent rate to decelerate) after the flight crew set the IM commanded speed in the mode control panel speed window. This mode on these particular aircraft meant any ABOVE altitude constraints would be met (the autothrottle would engage to increase engine speed); however, some AT or BELOW altitude constraints could only be met by pilot intervention (extending the speed brake to increase drag). VNAV speed is a mode pilots avoid using when flying an RNAV arrival, primarily because of the higher flight crew workload associated with managing the throttle and speed brake setting. In the third phase of the arrival scenarios, the flight crew used VNAV path with speed intervention to decelerate and configure the aircraft in the "approach mode."

\section{F. Flight Crew Surveys}

Following each scenario, an end-of-scenario survey with six questions was given to each pilot, of which the three questions discussed in Section III.b are:

1) Rate the overall acceptability of the IM operation

2) Rate the operational acceptability of the IM speeds

3) Was the aircraft's energy level acceptable on final

Following the final scenario of the day and its survey, the pilots were given an end-of-day survey with seven questions to complete, of which the three questions that contributed to the aggregated results in Section III.c are:

1) Describe changes you would make to the IM operation

2) Are there challenges to the implementation of IM into real-world operations?

3) Do the IM tasks integrate well with the normal operational flow of the flight deck?

\section{Flight Test Results}

During the nineteen days of the flight test, 144 data points (a successful scenario, or the IM operation as conducted in this test without controllers) were collected and used in the core analysis. An additional 13 data points were collected and used in a separate study on the impact of aircraft type and route design (not reported in this paper).

The data in sub-sections A and B describe results based on the 144 valid data points and their corresponding endof-scenario surveys, while the results in sub-section C are based on end-of-scenario and end-of-day surveys of all 204 data points. Since not every survey was returned ( $98 \%$ return rate) and not every question was completed by every pilot, the number of responses by question varies to a minor degree.

Of note is the fact that the IM flight crew procedures defined in the ATD-1 Concept of Operations ${ }^{2}$ and other NASA research ${ }^{6}$ were not followed during the flight test, which directly impacted pilot comments about the procedures in Section III.C.2 and makes direct comparison to previous simulation results challenging. The IM flight crew procedure was to set the Mach or airspeed shown on the IM equipment in the mode control panel speed window and allow the aircraft to decelerate or accelerate without continued pilot intervention, so that the pilot flying should only occasionally have to manipulate the throttle or speed brake to maintain vertical path. Three synergistic issues during the flight test caused the flight crew to elevate the importance of the FSI in their decision making process:

1) The IM avionics did not have access to the value set in the mode control panel speed window, therefore the MOPS conformance logic was used to trigger the flashing of the IM speed indicating to the flight crew that the aircraft was not decelerating or accelerating at a specified rate (the NASA approach used the flashing IM speed to cue the flight crew they had not set the airspeed),

2) The deceleration or acceleration rate used by the spacing algorithm did not always align with aircraft performance (the IM spacing algorithm conformed to the MOPS requirements, however significantly fewer rates than the NASA version used in previous simulation studies), and

3) The arrival and approach procedures were intended to be representative of procedures in place today and were to be acceptable for the use of speed as the primary control mechanism, however as designed the procedures kept the aircraft a little higher and faster than many pilots were accustomed to, and the 60 to 70 knot speed reductions were also reported as undesirable by many pilots.

The immediate consequence of these three issues was the logic to trigger the flashing of the IM speed was frequently met, indicating to the pilot that the deceleration or acceleration to the new IM speed was not occurring at the desired minimum rate. Because of this, during the first two weeks of the flight test the flight crew came to more fully appreciate the function of the FSI, and became more assertive trying to keep the FSI indication centered (indicating the deceleration or acceleration was as expected). The impact of modifying the briefed flight crew IM procedures was it led to very precise spacing performance, but the workload level associated with keeping the FSI centered (intervening with speed brake or throttle) was unacceptable for normal operations. 


\section{A. General Algorithm Performance}

\section{Spacing performance}

The spacing performance for the 129 time-based IM operations (6 en route, 118 arrival, and 5 final approach) and the 15 distance-based IM operations ( 5 en route, 7 arrival, and 3 final approach) is described in reference 14 . A cursory summary of some of those results include the spacing accuracy at the PTP for the time-based Maintain, Capture, and Cross-Merge arrival operations (77 of the 118) had means less than 1.2 seconds and standard deviations less than 3.0 seconds. The spacing accuracy at the ABP for the time-based Cross-Merge operations ( 25 of the 118 , and part of the 77 in previous statistic) had a mean of less than 1.7 seconds and standard deviation less than 6.3 seconds. More details about those statistics, and the remainder of the time-based IM operations and data on the distance-based IM operations are available in reference 14 .

\section{Example of nominal IM operation}

Figure 5 illustrates an example of a nominal IM operation that exhibited the desirable characteristic of few additional speed changes by the spacing algorithm (and therefore low impact to flight crew workload) and high aircraft delivery precision. During this scenario, the sequence of arrivals was the Falcon 900 on the ZIRAN.SUBDY1 arrival with no delay (at the published speeds), and the B-757 on the JELVO.SUBDY1 arrival conducting a Cross operation with no initial spacing error. The Cross operation was initiated just after the Target crossed SINGG and the Ownship crossed RIINO, the routes merged at NALTE (53 nmi from the PTP), and took 20.35 minutes to complete the operation. The ABP and PTP were collocated at the final approach fix (ZAVYO), therefore the trajectory-based spacing algorithm was used throughout the entire operation.

In the upper left airspeed panel, the Ownship (B-757, blue line), the Target (Falcon 900, red line), and the IM commanded end speed (yellow line) align well with the nominal published arrival and approach procedures (black line). The left center altitude panel illustrates that both aircraft flew almost identical vertical profiles and met all the altitude constraints (shown as blue triangles). The upper right and center right panels describe the lateral and vertical deviation from the published route of both the Ownship and Target aircraft. At $85 \mathrm{nmi}$ distance to go from the PTP, the Target aircraft deviated almost one nmi laterally and 1500 feet vertically from the published route, which was the result of the Target flight crew proceeding direct to NALTE shortly after crossing SINGG (bypassing SHARF) and commencing their descent later than planned. The shorter route of the Target caused the Ownship to move aft (late) relative to the assigned spacing goal as shown by the increase in the spacing error (green line in the lower left panel of Figure 5) from 2.6 seconds at $83 \mathrm{nmi}$ to 6.8 seconds at $79 \mathrm{nmi}$ to the PTP. The ten second spacing error increase from $68 \mathrm{nmi}$ to $42 \mathrm{nmi}$ and then decrease from $42 \mathrm{nmi}$ to $28 \mathrm{nmi}$ to the PTP was due to the Target's vertical deviation above path (red line in center right vertical deviation panel), with the higher ground speed typically produced at higher altitudes causing the Target to fly faster than the IM avionics expected, thereby making the Ownship fall behind (positive sign spacing error).

The spacing error increased from 0 to 5 seconds late when the Ownship was 22 to $17 \mathrm{nmi}$ to the PTP occurred when the Target was 10 to $6 \mathrm{nmi}$ from the PTP, which is the right turn onto final approach from HIXOS to ZETEK. The Target made this turn on vertical and lateral path, airspeed, however the Target's airspeed during this time was 10 knots faster than the nominal speed at $8 \mathrm{nmi}$ (red line in upper left airspeed panel), which causes the small increase in spacing error (green line in lower left panel) to 5 seconds late at $18 \mathrm{nmi}$.

The Ownship flight crew lowered the gear $9.7 \mathrm{nmi}$ from the PTP, causing the momentary drop in airspeed (blue line in upper left airspeed panel) until they added power to regain the IM commanded speed. They kept the throttles at a higher setting in order to keep the FSI centered until approximately $4 \mathrm{nmi}$ to the PTP, at which point they transitioned to achieving stabilized approach criteria and retard the throttles. This caused the Ownship airspeed to deviate from the nominal speed (black line), in turn causing the aircraft to go from 2 seconds ahead of the goal to 6.1 seconds behind the goal (green line in lower left panel). [Note: once the Target crossed the PTP, which occurred when the Ownship was $10.6 \mathrm{nmi}$ from the PTP, the spacing algorithm uses the nominal profile speed after that point for its calculations.]

Both pilots also rated the acceptability of the IM speeds on this scenario as acceptable (' 6 ' on a 7-point Likert scale described in the next section). Those 'acceptable' ratings, coupled with the IM operation only requiring the same number of speed changes as the published procedure, are indications that the design goal of minimizing impact to flight crew workload was achieved. However, one of the two pilots remarked that the IM speed change of 270 to 210 knots was very large, while the other pilot remarked that the energy level on final was too high (supported by the blue line in the upper left panel). 


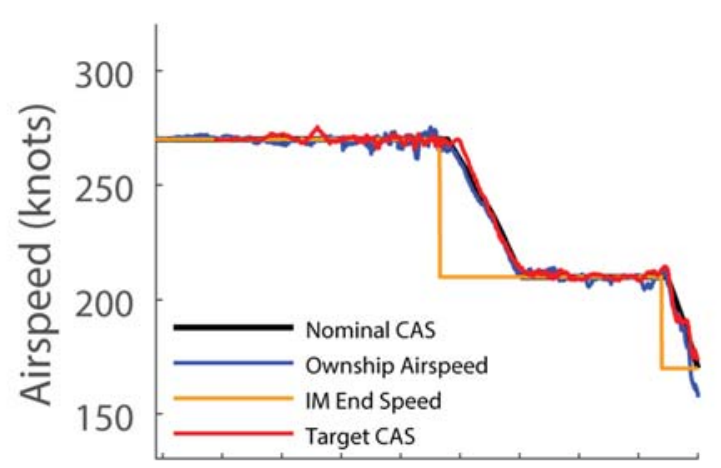

$908070605040302010 \quad 0$
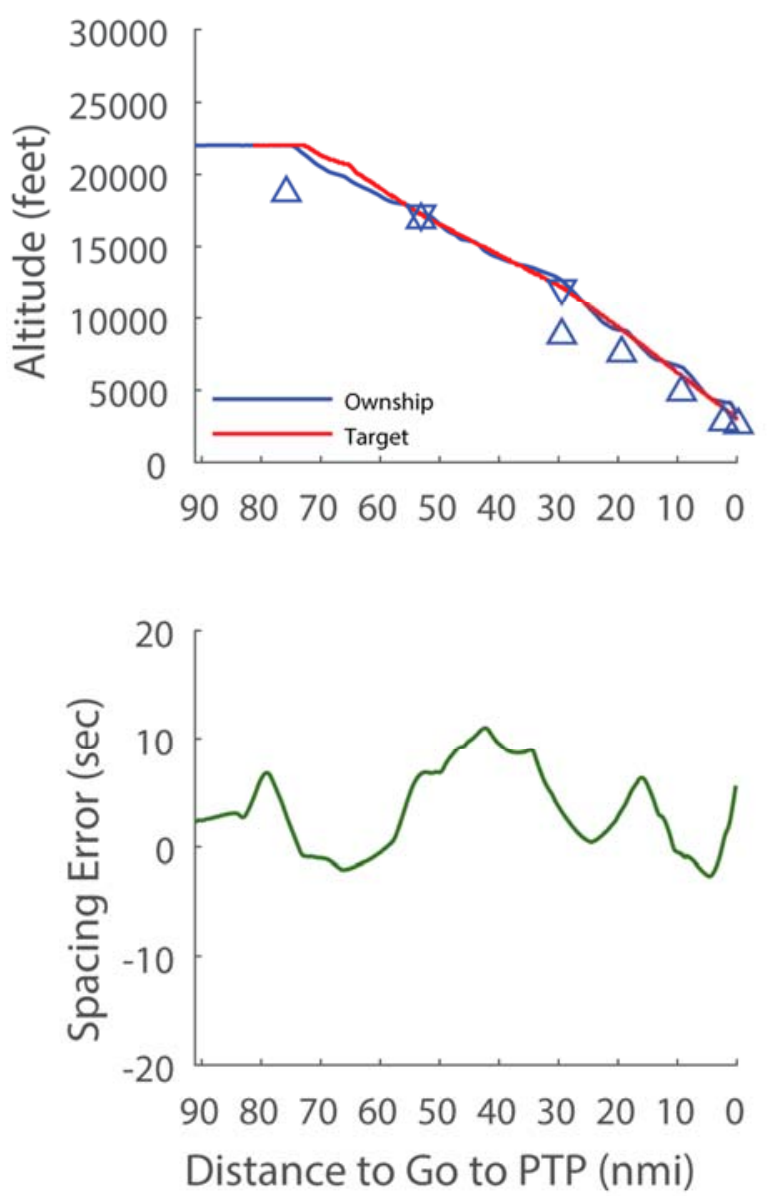
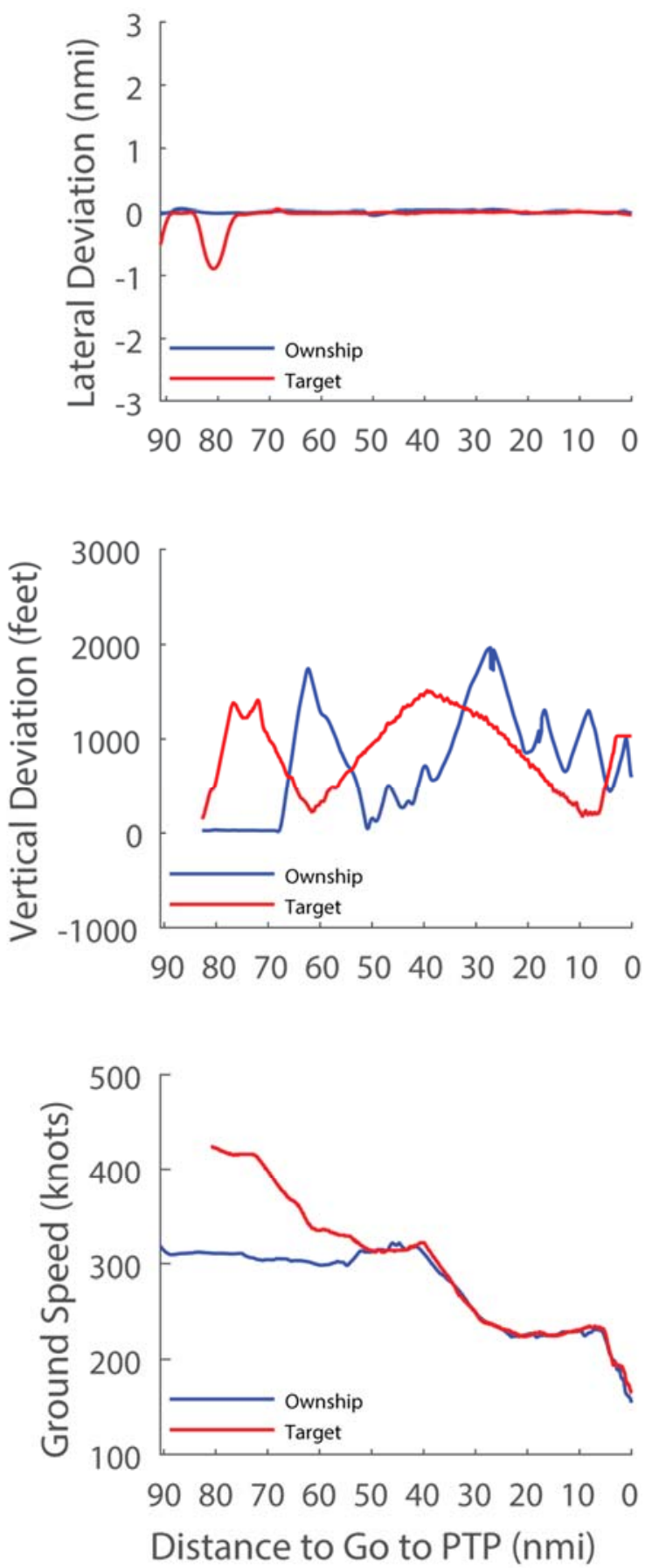

Figure 5. Nominal IM Cross operation with aircraft merging at $53 \mathrm{nmi}$.

In summary, this nominal IM operation highlights several issues to be addressed for the IM concept and software to move forward towards implementation into real world operations:

1) The spacing error value is primarily driven by changes in the ground speed deviation of the Ownship and Target aircraft when the trajectory-based speed control law is used, as was the case in this example of a Cross operation. This means the spacing error is sensitive to variations in either aircraft's lateral path, vertical path, and airspeed (typically less than 1000 feet vertical and 5 knot speed difference in this example). The flight crews' performance in this particular scenario was well within expected parameters, 
but the resulting profile of the spacing error would most likely have triggered additional IM speed changes had the algorithm been using the constant-time delay versus the trajectory-based operation control law.

- Additional analysis is being conducted to determine if there was also a correlation when the Ownship's or Target's heading changed caused a significant enough change in ground speed (due to different headwind components) that additional IM commanded speed changes occured.

2) The design of the arrival and approach procedures required a very large speed reduction during the arrival (60 to 70 knots), kept the aircraft faster on final than the flight crew were accustomed to or felt comfortable with, and required a very large speed reduction on approach just prior to PTP in order to achieve stabilized approach criteria (210 to 170 knots at $6 \mathrm{nmi}$ to the PTP). The procedures did not meet the goal of being representative of typical PBN procedures, and this significantly impacted the results of the test. Desired characteristics for arrival and approach procedures to support IM operations should include:

- From an aerodynamic perspective, the nominal airspeeds should be close to the center of the aerodynamic envelope to allow for fuel efficient acceleration or deceleration, and must ensure stabilized approach criteria will be met.

- From a human factors perspective, the flight crew reported large speed reductions in contemporary operations may indicate an impending loss of aircraft separation with the preceding aircraft, therefore speed brakes or lowering the gear (if appropriate) early may be used to expedite achieving the new speed. Although it wasn't an issue in any of the ATD-1 flight operations, the flight crew were not able to consistently overcome that thought during the flight test, resulting in many instances where the IM aircraft decelerated too quickly due to the instinctual use of speed brake or lowering the gear to assist achieving the large speed reduction. Flight crew feedback suggested decelerations no greater than 40 knots during descent and no greater than 20 knots on final would be more appropriate for normal operations.

3) In a normal operational environment, many flight crews use specific distance to go points to decelerate and configure the flaps or lower the gear. The IM spacing algorithm changes the commanded speed when the spacing error reaches a certain threshold, which makes the speed changes less predictable and inconsistent as a function of distance to go. The consequence is that flight crews no longer have a normal cadence to manage cockpit tasks in a logical sequence or time, and on this particular scenario, lowered the gear much sooner than required at $9.7 \mathrm{nmi}$ (due to higher airspeed than desired, and in anticipation of the pending large speed reduction).

4) The deceleration rate used by the spacing control law during the flight test was not sufficiently close to actual aircraft performance throughout the entire operation regardless of descent angle or aircraft configuration. This issue had two consequences:

- The flight crew frequently had to use speed brake during the descent (assumed deceleration rate too high) and add power on final (assumed deceleration too small when flaps or gear deployed).

- The logic to flash the IM speed on the EFB and CGD was frequently triggered, indicating the current airspeed was not correct despite having executed the IM procedure properly. Searching for different ways to improve the performance of the IM operation, the flight crew found that by keeping the FSI centered (aircraft speed matching the IM instantaneous speed), frequently resulted in spacing performance of 2 seconds or less. The end result was that flight crews compensated for the incorrect deceleration rate and the flashing IM speed by developing a technique of pilot intervention using speed brake and throttle, which was a considerably higher workload than the planned flight crew procedures.

\section{B. Quantitative Survey Responses}

\section{1. "Overall acceptability of the IM operation"}

The flight crew overall acceptability of the IM operation was measured using a 7-point Likert rating scale ranging from ' 1 ' = "Completely Unacceptable" to '7' = "Completely Acceptable." Data were collected from each of the subject pilots via post-scenario questionnaires in order to assess the a priori hypothesis that pilots will report the mean acceptability of IM operations greater than or equal to ' 5 '.

Statistical analysis was performed using the Wilcoxon signed rank test, a nonparametric test appropriate for analyzing ordinal data. ${ }^{20}$ For all IM operation types, the mean overall acceptability ratings were statistically significantly greater than ' 5 ' $(\mathrm{p} \leq 0.018)$, indicating that flight crews found the operations to be acceptable overall (column \#1 in Table 2). 
Some of the issues identified belong more logically to other questions, however responses shown are as given by the flight crew on the survey. The major issues identified with "overall acceptability of the IM operations" were:

- $\quad$ Large decelerations

- Too many speed changes

- Too fast when close to the final approach fix

- Accelerate on final and raise the flaps

- Too much pilot intervention using throttle and speed brake to maintain vertical profile

- IM speed caused high energy state that was outside RNAV vertical path requirements

\section{2. "Operational acceptability of the IM speed"}

The flight crew operational acceptability of the IM speed was also measured using a 7-point Likert rating scale via post-scenario questionnaires in order to assess the a priori hypothesis that pilots will report the mean operational acceptability of IM speeds greater than or equal to ' 5 '.

Statistical analysis indicated that flight crews found the IM speeds to be operationally acceptable overall with mean operational acceptability ratings of the IM speeds were statistically significantly greater than ' 5 ' for all three clearance types $(\mathrm{p} \leq 0.025)$ (column \#2 in Table 2).

Some of the issues identified belong more logically to other questions, however responses shown are as given by the flight crews on the surveys. Furthermore some pilots made two are three comments within the response field when that occurs, each individual comment is added to the respective category below. The major issues identified with "overall acceptability of the IM speed" were:

- $\quad$ Large decelerations

- Too many speed changes

- Too fast when close to the final approach fix

- Accelerate on final and raise the flaps

- Too much pilot intervention using throttle and speed brake to maintain vertical profile

- IM speed caused high energy state that was outside RNAV vertical path requirements

- Too slow during the descent

- Deceleration rate not accurate

\section{3. "Aircraft energy level on final acceptable"}

The flight crew acceptability of the aircraft's energy level on final was measured using a 'Yes' = "Acceptable" or 'No' = "Unacceptable" response. Since flight crew are required to execute a "go-around" if stabilized approach criteria are not met from 1000 feet above ground level to the surface (specified in each airlines' Operations Specification manual to comply with FAA Order 8900.1), the research team set a subjective criteria of greater than $95 \%$ of the responses must be "Yes" for the operation to be acceptable (greater than 10 knots above the final approach airspeed does not meet the "stabilized approach" criteria).

The IM operations did not meet the subjective criteria of greater than $95 \%$ of the responses reporting the aircraft's energy level on final approach to be acceptable (column \#3 in Table 2).

Flight crew comments about whether or not the "aircraft energy level on final is acceptable" included being too fast or initiating final deceleration too late, having to use the speed brake and gear to assist in the final deceleration, and difficulty achieving the IM speed while maintaining vertical path.

Table 2. Statistics for quantitative survey responses

\begin{tabular}{|c|c|c|c|c|c|c|c|c|c|c|c|}
\hline \multirow{2}{*}{ Scenario } & \multirow{2}{*}{$\begin{array}{c}\text { Clearance } \\
\text { Type }\end{array}$} & \multirow{2}{*}{$N$} & \multicolumn{2}{|c|}{ \#1. IM Operation } & \multicolumn{2}{|c|}{ \#2. IM Speed } & \multirow{2}{*}{$N$} & \multicolumn{4}{|c|}{ \#3. Energy on final acceptable } \\
\hline & & & Mean & SD & Mean & SD & & Yes & (\%) & No & $(\%)$ \\
\hline \multirow{2}{*}{ En route } & Maintain & 13 & 6.6 & 0.5 & 6.7 & 0.5 & \multirow{2}{*}{$\mathrm{n} / \mathrm{a}$} & \multirow{2}{*}{$\mathrm{n} / \mathrm{a}$} & \multirow{2}{*}{$(-)$} & \multirow{2}{*}{$\mathrm{n} / \mathrm{a}$} & \multirow{2}{*}{$(-)$} \\
\hline & Capture & 6 & 6.5 & 0.5 & 6.5 & 0.5 & & & & & \\
\hline \multirow{3}{*}{ Arrival } & Maintain & 31 & 5.9 & 1.1 & 5.5 & 1.3 & 30 & 23 & (77) & 7 & (23) \\
\hline & Capture & 58 & 6.1 & 0.7 & 5.9 & 0.9 & 54 & 48 & (89) & 6 & (11) \\
\hline & Cross & 137 & 5.9 & 1.0 & 5.6 & 1.2 & 134 & 118 & (88) & 16 & (12) \\
\hline $\begin{array}{c}\text { Final } \\
\text { Approach }\end{array}$ & Final & 15 & 6.3 & 0.8 & 6.5 & 0.5 & 14 & 12 & (86) & 2 & (14) \\
\hline
\end{tabular}




\section{Qualitative Survey Responses}

1. Comments about the Spacing Algorithm Performance

Five significant comments about the spacing algorithm performance from all surveys responses were:

1) Aircraft too fast on final to achieve a stabilized approach

2) IM speed changes with a large magnitude difficult to manage and imply an impending conflict

3) Too many IM speed changes or the rate of speed changes is too high

4) IM speed reversals are inefficient, and if flaps must be raised are operationally unacceptable

5) IM acceleration/deceleration rate does not seem to be always accurate

The IM operation shown in Figure 6 illustrates some of these comments. During this scenario, the Falcon 900 Target aircraft was on the JELVO.SUBDY1 simulating high delay by flying the procedures 10 to 20 knots slower than the published speeds (red line in upper left airspeed panel), the B-757 Ownship was also on the JELVO.SUBDY1, and the Maintain operation was initiated with the Target just prior to SUBDY. The IM avionics on the Ownship calculated a 171-second measured spacing interval, which translated to $14.3 \mathrm{nmi}$ in trail at initiation and $9.6 \mathrm{nmi}$ when the Target crossed the PTP.
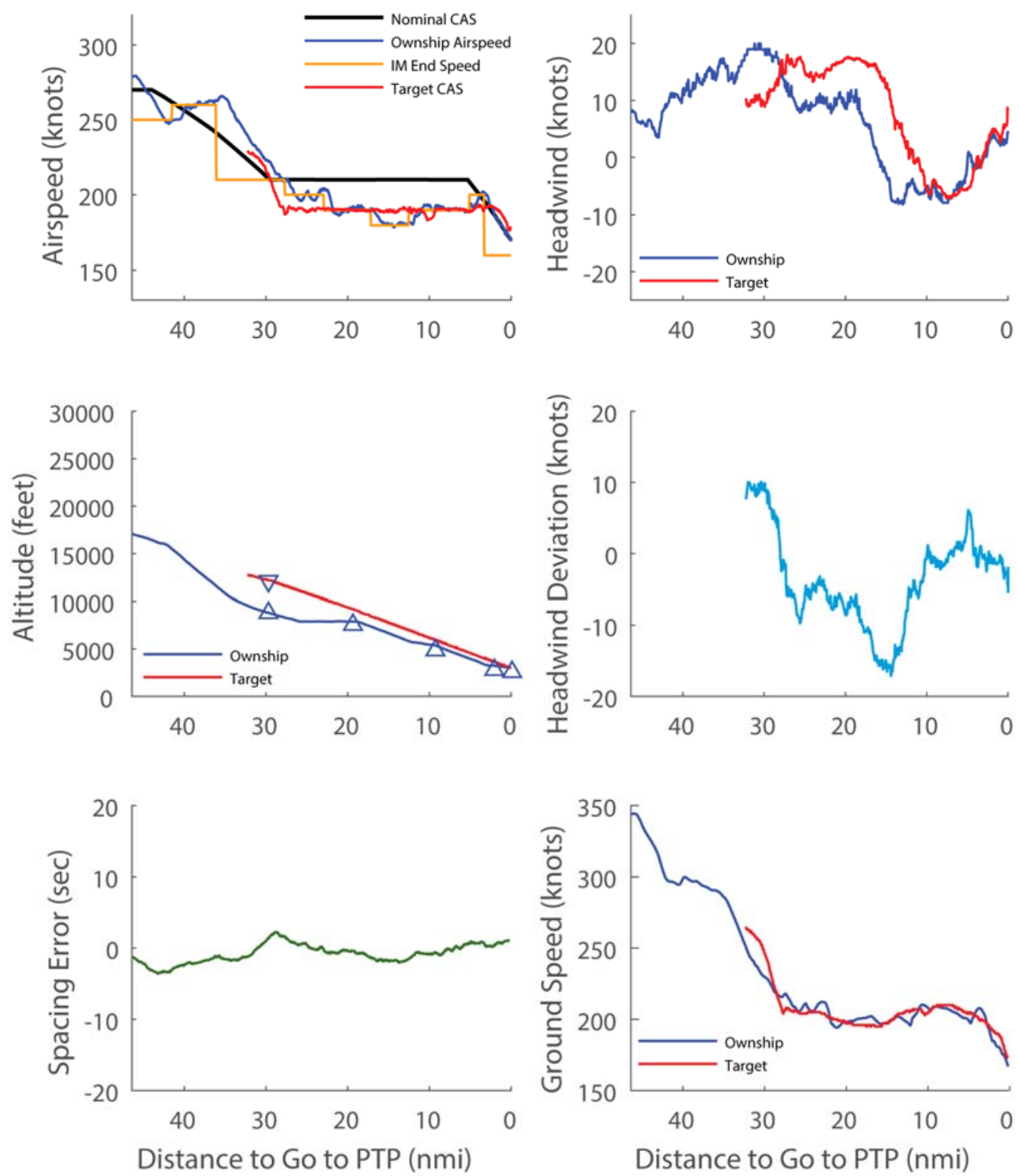

Figure 6. Maintain operation with many speed changes and reversals. 
Of note is while both aircraft met the altitude constraints of the arrival and approach, the Target (red line in center left altitude panel) flew the procedures differently and slightly higher than the Ownship (blue line in center left altitude panel). This resulted in the aircraft being subjected to different headwind components when crossing the same point (upper right headwind panel), at times as much as a 17 knot difference between the two aircraft (middle right headwind deviation panel), which was a significant factor in the different ground speed plots of the aircraft (bottom right panel).

In a Maintain operation when subjected to unexpected deviations from the nominal ground speed of aircraft, the IM spacing algorithm issues a speed change (orange line in upper left airspeed panel) to keep the spacing error (green line in lower left spacing error panel) minimized. While the relatively small variations in the spacing error are desirable, operationally the number of IM speed changes was not desirable, and the speed increases on final were not acceptable. [Note: While the NASA version of the spacing algorithm used in previous experiments had code to minimize speed changes and speed reversals that the flight test software did not, the higher rate of speed changes when using the constant-time delay control law has been previously identified as a challenge and a benefit to using the trajectory-based control law.]

\section{Comments about the Flight Crew IM Procedures}

Some of the comments in this section were heavily influenced by the previously noted procedure modification the flight crew devised to aggressively follow the FSI (compensation for the IM software not having knowledge of the value set in the Mode Control Panel speed window and the deceleration rate not closely aligning to actual aircraft performance), and by the arrival and approach procedures that were designed to have few speed changes (and therefore large magnitudes) and slightly higher than normal speeds on final. The comments are valid and need to be addressed in future research and testing, however care must be exercised to ensure the issue is addressed by the appropriate function (route design, IM avionics requirements, or speed control law implementation).

Four significant comments from the flight crew about the IM procedures were:

1) Using VNAV speed to conduct an IM operation is high workload due to frequent pilot intervention required to maintain vertical path and speed

- Large magnitude speed changes are more difficult to execute and frequently interpreted as possible impending aircraft separation issue (as is typically the case in operations today)

- Having no fore-knowledge of when or what the next IM speed would be meant the flight crew could only be reactive, which becomes problematic when configuring the aircraft for landing

2) The arrival and approach procedures should be tailored to better meet the energy management requirements of IM operations

- The nominal airspeed should be towards the center of the aerodynamic performance, thereby allowing both speed increases and decreases to be efficient

- The nominal airspeed changes should allow for gradual speed reductions (suggested by some flight crew to be no greater than 40 knots during the descent and no greater than 20 knots on final)

- The descent angle should be shallow enough that some thrust greater than idle is required in most wind conditions (to avoid excessive use of speed brake)

- The nominal speeds on final need to ensure stabilized approach criteria can be met even when responding to a change to the IM commanded speed

3) Deceleration in VNAV speed just prior to an altitude constrained waypoint may not be acceptable

- Either an alternative flight mode could be used to conduct IM operations, or a requirement should be considered to ensure when using VNAV speed that an IM speed deceleration immediately prior to an altitude constrained waypoint will not require the flight crew to use substantial speed brake to achieve both the IM speed and the altitude constraint

4) Workload to enter data required for the IM operation is too high for normal operations

- There were several occasions where it took five minutes to manually enter Ownship information, forecast winds, and IM clearance information ( 80 to 110 button presses on the EFB depending on clearance type) while simultaneously accomplishing other cockpit tasks

- Pilots frequently cited the time required for the monitoring pilot to enter data was too long, and the data entry process too complex

- Some pilots postulated that a data comm capability to electronically transmit the information and to enable the flight crew to load the information into the avionics with just a few button presses, would substantially alter the time and workload and thereby potentially make it acceptable 


\section{Conclusion}

Overall the IM spacing algorithm and procedures worked well across a wide range of operating environments and IM clearance types, and the goals of 1) developing avionics hardware and software for the IM operations, and 2) integrating those avionics into two aircraft to conduct a flight test were met. The software demonstrated it is capable of spacing accuracy goals for time-based and distance-based IM operations, and more in-depth analysis is ongoing to determine the root cause for those operations that did not meet the desired goal. Issues identified by the subject pilots and the research team that directly impacted the results but are not part of the IM avionics were:

- The design of the arrival and approach procedure must be tailored to support operations designed to use speed as the primary mechanism to achieve the spacing interval. This includes: speeds in the center of the aerodynamic envelope, changes in speed constraints no larger than 40 knots at altitude or 20 knots on final, altitude windows to allow for variations in aircraft weight and head wind component, and speeds slow enough on final to ensure stabilized approach criteria will be achieved when required.

- This bullet is a reflection of the route design, not the spacing algorithm or its requirements.

- Conducting the flight test without the other two ATD-1 technologies (ground scheduler and controller decision support tools) resulted in many of the runs having shorter valid IM operations due to the challenges of setting up the timing to initiate a scenario without the controllers' assistance.

- Conducting IM operations without a data comm capability to enable the flight crew to electronically upload the forecast wind information and IM clearance information is not realistic for normal operations.

Key issues identified by the subject pilots for the IM spacing algorithm and flight crew procedures include:

- The frequency of IM speed commands (sometimes two or three times the rate of controller speed changes) and frequency of speed reversals (accelerations) is not operationally reasonable.

- The deceleration rate used by the spacing algorithm did not always align well to the actual aircraft performance, causing the IM speed to flash (indicating to the flight crew the procedure was not progressing as desired), and additional speed changes were generated, with some of them highly undesirable accelerations requiring a change to the flap setting. Eventually the flight crew incorporating the FSI which in turn made the workload operationally unacceptable (throttle, speed brake).

- Minor variations in the vertical path or headwind experienced by the Target and Ownship to be expected in typical real-world operations are sufficient to trigger additional IM speed changes and speed reversals.

$\circ$ This is shown in example $\# 2$ as a problem on final, but could theoretically occur anywhere.

- The use of the VNAV speed mode to conduct an IM operation (the flight crew manage throttle and speed brake to maintain vertical path while achieving the IM commanded speed) is not realistic for normal operations.

In summary, the software demonstrated great promise to contribute to an integrated arrival operation by precisely delivering aircraft to a specified point at a specific interval behind the Target aircraft. Several critical design criteria and enabling infrastructure requirements were identified for operational implementation of IM, and some key IM software issues were described that need to be addressed prior to the next simulation or flight test.

\section{Acknowledgments}

The authors are indebted to many NASA, Boeing, Honeywell, and United Airlines people who went above and beyond what was asked of them to make this flight test successful, and without their contributions the flight test would not have been possible. In particular the Honeywell software team in Redmond, WA and Bangalore, India deserve special recognition. In addition to the people part of the ATD-1 contracting team, the flight test was also immeasurably assisted by many FAA organizations, including the SBS office, ANG, ANM-220, and five Branches in the AFS-400 Division. Finally, the professionalism and skill of the controllers, especially Washington Center, was incredible and they have rightfully earned the reputation as the premier place to go for flight testing air traffic management concepts.

\section{References}

\footnotetext{
${ }^{1}$ Baxley B., Swenson H., Prevot T., Callantine T., "NASA's ATM Technology Demonstration-1: Integrated Concept of Arrival Operations," 31 ${ }^{\text {st }}$ Digital Avionics Systems Conference (DASC), IEEE/AIAA, Williamsburg, VA, 2012.

${ }^{2}$ Baxley, B., Johnson, W., Scardina, J., Shay, R., "Air Traffic Management Technology Demonstration-1 Concept of Operations (ATD-1 ConOps), Version 3.0,” NASA/TM-2016-219213.

${ }^{3}$ Witzberger, K., Martin, L., "Paradigm Changes Related to TSAS," Journal of Air Traffic Control, Winter 2015, pp. 38-46.
} 
${ }^{4}$ Baxley, B., et al., "Human-in-the-Loop Assessment of Alternative Clearances in Interval Management Arrival Operations," NASA/TP-2016-219362.

${ }^{5}$ Baxley, B., Wilson, S., Roper, R., Swieringa, K., "Flight Crew Responses from the Interval Management Alternative Clearances (IMAC) Human-In-The-Loop Experiment," $16^{\text {th }}$ AIAA Aviation Technology, Integration, and Operations Conference (ATIO), AIAA 2016-3299, Washington, D.C., June 2016.

${ }^{6}$ Swieringa, K., Wilson, S., Baxley, B., "System Performance of an Integrated Airborne Spacing Algorithm with Ground Automation," $16^{\text {th }}$ AIAA Aviation Technology, Integration, and Operations Conference (ATIO), AIAA 2016-3900, Washington, D.C., June 2016.

${ }^{7}$ Scharl, J., "NASA ATD-1, Avionics, Phase 1 Final Report, Task Order Number: NNL12AC59T," Boeing Research and Technology, and Boeing Commercial Airplanes, Document D780-10378-1, 22 April 2013. [NASA CR submitted for publication]

${ }^{8}$ Roper, R., "ATD-1 EcoDemonstrator ASTAR Guided Arrival Research (EAGAR)," NASA Briefing, Document ID 20160006919 (available on ntrs.nasa.gov), Jan 2015

${ }^{9}$ Roper, R., Koch, M., “ASTAR Flight Test: Overview and Spacing Results," AIAA Guidance, Navigation, and Control Conference, AIAA 2016-1614, San Diego, CA, Jan 2016

${ }^{10}$ Brown, J., "NASA ATD-1 Avionics Phase 2 Flight Test Plan,”NASA/CR-2017-219595.

${ }^{11}$ Boyle, D., Rein-Weston, K., Berckefeldt, R., Eggling, H., Stankiewicz, C., Silverman, G., “ATD-1 Avionics Phase 2 Flight Test: Flight Test Operations and Safety Report (FTOSR)," NASA/CR-2017-219592.

${ }^{12}$ Hicok, D., Barmore, B., "Concept of Operations for Interval Management Arrivals and Approach," AIAA SciTech 2017, San Diego, CA, Jan 2016.

${ }^{13}$ Barmore, B., Penhallegon, W., Weitz, L., Bone, R., Levitt, I., Flores Kriegsfeld, J., Arbuckle, D., Johnson, W., "Interval Management: Development and Implementation of an Airborne Spacing Concept," AIAA SciTech 2017, San Diego, CA, Jan 2016.

${ }^{14}$ Swieringa, K., Wilson, S., Baxley, B., Roper, R., Abbott, T., Levitt, I., Scharl, J., "Flight Test Evaluation of the ATD-1 Interval Management Application," $17^{\text {th }}$ AIAA Aviation Technology, Integration, and Operations Conference (ATIO), AIAA 20172645387, Denver, CO, June 2017.

${ }^{15}$ Abbott, T., "An Overview of a Trajectory-Based Solution for En Route and Terminal Area Self-Spacing: Eight Revision," NASA/CR-2017-xxxxxx, submitted for publication.

${ }^{16}$ RTCA SC-186, "Minimum Operational Performance Standards (MOPS) for Flight-deck Interval Management (FIM)," DO361, Sept 2015.

${ }^{17}$ Alves, E., "FIM Avionics Operations Manual," NASA/CR-2017-219593.

${ }^{18}$ Wilber, G., "ATM Technology Demonstration-1 Phase II Boeing Configurable Graphical Display (CGD) Software Design Description," NASA/CR-2017-219594.

${ }^{19}$ Baxley, B., Palmer, M., Swieringa, K., "Cockpit Interfaces, Displays, and Alerting Messages for the Interval Management Alternative Clearances (IMAC) Experiment," NASA/TM-2015-218775.

${ }^{20}$ Hollander, M., Wolfe, D., "Nonparametric Statistical Methods," John Wiley \& Sons, New York, NY $2^{\text {nd }}$ edition, 1999. 